УДК $669.184 ; 669.046$

А.А. Похвалітий, асистент кафедри металургії чорних металів

Є.М. Сігарьов, д.т.н., зав. кафедри металургії чорних металів

К.І. Чубін, к.т.н., доцент кафедри металургії чорних металів

В.П. Полєтаєв, к.т.н., доцент кафедри металургії чорних металів

О.В. Похваліта, студентка

Дніпровський державний технічний університет, м. Кам’янське

\title{
МАТЕМАТИЧНА МОДЕЛЬ ФОРМУВАННЯ ГАЗОМЕТАЛЕВОГО ПОТОКУ У СТАЛЕВИПУСКНОМУ КАНАЛІ КОНВЕРТЕРА
}

Представлені результати математичного моделювання процесу випуску металевого розплаву за умов одночасного вдування нейтрального газу у потік у межах сталевипускного каналу кисневого конвертера. Із використанням результатів фізичного моделювання розроблені математичні моделі для опису впливу витратних характеристик нейтрального газу, розтамування сопел для вдування останнього та геометричних параметрів сталевипускного каналу на формування газометалевого потоку. Визначені раціональні параметри формування й структури газометалевого потоку із створенням захисної атмосфери та забезпеченням процесу вуглецевого розкислення.

Ключові слова: математична модель, сталевипускний канал, розкислення, нейтральний газ, металевий розплав.

The results of mathematical modeling of the metal melt release process under the conditions of simultaneous injection of neutral gas into the flow within the steel-tapping channel of the oxygen converter are presented. Using the results of physical modeling, mathematical models are proposed to describe the effect of the consumption characteristics of a neutral gas, the placement of nozzles for injecting the latter and the geometric parameters of the steel-tapping channel to form a gas-metal flow. The rational parameters of the formation and structure of the gas-metal flow are established with the maintenance of the protective atmosphere and the carbon deoxidation process.

Keywords: mathematical model, steel-tapping channel, deoxidation, neutral gas, metallic melt.

\section{Постановка проблеми}

Отримання марок сталі відповідального призначення в більшості випадків вимагає забезпечення особливо низького залишкового вмісту розчинених газів та шкідливих домішок, у тому числі кисню (менше $15 \mathrm{ppm})$ та сірки (30-100 ppm). Вміст вказаних домішок в готовому продукті в значній мірі залежить не тільки від загального рівня технології виплавки, позапічної обробки та розливання, а і від ступеня досконалості технології захисту розплаву від контакту з атмосферою на стадіях випуску та переливу. Вдосконалення технології випуску розплаву з урахуванням можливості використання рафінувального потенціалу сталевипускного каналу кисневого конвертера $є$ актуальним завданням.

У роботах [1-3] запропоновано операцію вуглецевого розкислення нерозкисленої сталі виконувати в процесі випуску розплаву з конвертера, шляхом організації продування металевого потоку інертним газом (аргоном) у робочому просторі сталевипускного каналу. Такий прийом дозволяє зменшити тиск і витрату нейтрального газу, використати вуглецевий потенціал залізовуглецевого розплаву та зменшити ресурсо- та енерговитрати на отримання готової металопродукції.

\section{Аналіз останніх джерел досліджень і публікацій}

У роботах [1-4] представлені результати фізичного моделювання процесу випуску 3 обробкою рідини газом у порожнині сталевипускного каналу. В той же час, представлений в роботі [2] опис процесу має, в основному, якісний характер. Підхід до кількісної оцінки взаємозв'язку основних конструктивних параметрів і режимів подачі нейтрального газу із застосуванням методу діаграм зв'язків наведений в роботі [1]. 
У відомих на сьогодні дослідженнях практично відсутні відомості щодо математичного опису процесу випуску розплаву з організацією одночасного розкислення, який би враховував особливості формування газометалевого потоку у сталевипускному каналі кисневого конвертера.

Відповідно до прийнятих параметрах експерименту та установки фізичного моделювання [3] сталевипускний канал діаметром $d_{0}=30$ мм і довжиною $l_{0}=400$ мм був обладнаний соплами для вдування нейтрального газу діаметром $d_{\mathrm{C}}=2,3$ мм. Сопла були розташовані в сталевипусному каналі на відстані $l_{\mathrm{C} .1}=120$ мм і $l_{\mathrm{C} .2}=300$ мм від нижнього зрізу каналу. Відношення $l_{\mathrm{C}} / d_{0}$ умовно прийняте у якості відносної довжини умовної реакційної зони, у межах якої формується газорідинний потік та протікає вуглецеве розкислення розплаву. Витрата нейтрального газу прийнята в межах $Q_{\mathrm{g}}=0,1 \ldots 0,6 \mathrm{~m}^{3} /$ хвил. Окрім того, у серії досліджень $[3,4]$ використовували одно- та багатокамерні конструкції сталевипускного каналу.

\section{Формулювання мети дослідження}

Метою роботи є розробка математичних моделей та чисельне моделювання процесу випуску розплаву із визначенням впливу витратних характеристик нейтрального газу і геометричних параметрів сталевипускного каналу кисневого конвертера на формування газорідинного потоку (ГРП) та можливості захисту останнього від атмосферного впливу.

\section{Матеріали досліджень}

У ході виконання першого етапу досліджень комплексного впливу геометричних параметрів та режимів подачі нейтрального газу у робочий простір сталевипускного каналу на формування газорідинного потоку та його структуру отриманий масив даних [3] для розробки математичної моделі процесу.

Для визначення математичної залежності використана система рівнянь, представлена наступним чином:

$$
Z(x, y)=\left\{\begin{array}{l}
a y^{2}+b y+c \\
a=a_{1} x+a_{2} \\
b=b_{1} x+b_{2} \\
c=c_{1} x+c_{2}
\end{array} x \in\left(x_{0}, x_{n}\right) ; y \in\left(y_{0}, y_{m}\right) .\right.
$$

Після виконання відповідних математичних перетворень та з використанням даних [3] впливу витрати нейтрального газу та довжини реакційної зони на тривалість випуску утвореного газорідинного потоку отримали математичну модель

$$
\begin{gathered}
Z(x, y)=1.9 x+141.4 y-29.98 x y^{2}-141.4 y^{2}+29.98 x y+56.2 \\
\text { при } 4 \leq x \leq 10,0.1 \leq y \leq 0.6 .
\end{gathered}
$$

Результати чисельного моделювання з використанням моделі (2) представлені на рис. 1.

Отримана залежність (рис. 1) має складний, нестаціонарний характер. Встановлено (рис. 1), що тривалість випуску газорідинного потоку при рекомендованій у попередніх експериментах [1] витраті газу $\left(0,4 \mathrm{~m}^{3} /\right.$ хвил) перевищує прийняту базову тривалість випуску сталі 3 конвертера $\left(\tau_{0}=60\right.$ сек) і сягає $120 \ldots 180$ сек. Таке збільшення тривалості випуску розплаву 3 конвертера $є$ технологічно недоцільним.

Так, наприклад, у перерахунку на умови випуску розплаву з 260-т конвертера за таких умов тривалість операції збільшиться з 10 хвилин до $20 \ldots 30$ хвилин. Крім того було виявлено, що ступінь організації газорідинного потоку зменшується після проходження екстремуму з витратою нейтрального газу $0,2 \mathrm{~m}^{3} /$ хвил. (для $l_{\mathrm{C}} / d_{0}=4$ ) та $0,3 \mathrm{~m}^{3} /$ хвил. (для $l_{\mathrm{C}} / d_{0}=10$ ).

У наступній серії експериментів [3], з метою пошуку шляхів вирішення проблеми збільшення тривалості випуску, збільшили діаметр реакційної зони (до 50 мм) (використали сталевипускний канал двокамерної конструкції). Сопла у каналі були розташовані на відстані 100 мм, 200 мм і 300 мм, що відповідало відносній довжині реакційної зони 2, 4 і 6 відповідно.

Отримані у ході експериментів описані математичною залежністю, яка має вигляд

$$
\begin{gathered}
Z(x, y)=26.37 y-0.075 x-20.98 x y^{2}-34.8 y^{2}+25.96 x y+40.05 \\
\text { при } 2 \leq x \leq 6,0.1 \leq y \leq 0.6 .
\end{gathered}
$$




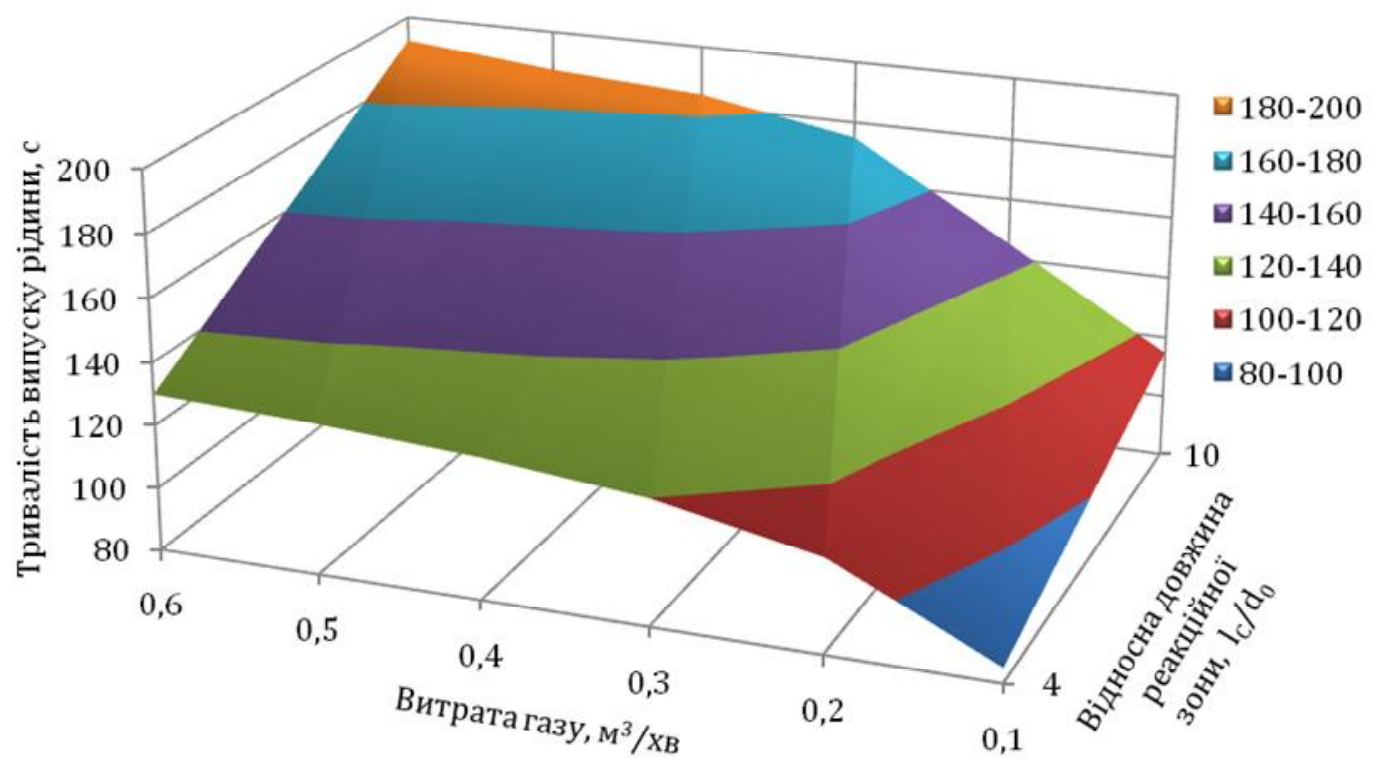

Puc. 1. Вплив витрати нейтрального газу та довжини реакційної зони на тривалість випуску газорідинного потоку для однокамерного сталевипускного каналу $\left(d_{0}=30\right.$ мм)

Результати чисельного моделювання із використанням моделі (3) представлені на рис. 2.

Встановлено (рис. 2), що за умов застосування двокамерної конструкції сталевипускного каналу [5], тривалість випуску газорідинного потоку, при рекомендованій витраті газу $\left(0,4 \mathrm{~m}^{3} / \mathrm{xв}\right)$ [1], відповідає прийнятій початковій (для $\left.l_{\mathrm{C}} / d_{0}=2\right)$ і збільшується у 1,2 і 1,5 рази для $l_{\mathrm{C}} / d_{0}=4 \mathrm{i} l_{\mathrm{C}} / d_{0}=6$ відповідно. Отримані характеристики відповідають технологічному регламенту операції випуску розплаву з кисневого конвертера.

Зменшення ступеня організації ГРП (кута його розкриття) відбувається при проходженні екстремуму 3 витратою нейтрального газу $0,25 \mathrm{~m}^{3} /$ хвил. (для $l_{\mathrm{C}} / d_{0}=2$ ), $0,35 \mathrm{~m}^{3} /$ хвил. (для $l_{\mathrm{C}} / d_{0}=4$ ) та $0,4 \mathrm{~m}^{3} /$ хвил. (для $l_{\mathrm{C}} / d_{0}=6$ ) відповідно.

Отримана математична залежність, яка характеризує вплив витрати нейтрального газу на кут розкриття потоку при різній відносній довжині реакційної зони має вигляд

$$
\begin{gathered}
Z(x, y)=23.66 y-0.16 x+2 x y^{2}+11 y^{2}-5.23 x y+2.35 \\
\text { при } 2 \leq x \leq 6,0.1 \leq y \leq 0.6 .
\end{gathered}
$$

Результати чисельного дослідження впливу витрати нейтрального газу на ступінь організації ГРП представлені на рис. 3.

Необхідно відмітити (рис. 3), що зі зменшенням довжини реакційної зони збільшується кут розкриття газометалевого потоку на виході з каналу. Збільшення витрати нейтрального газу призводить до зменшення ступеня організації потоку. При довжині реакційної зони $l_{\mathrm{C}} / d_{0}=6$ та витратах нейтрального газу у дослідженому діапазоні $\left(0,1 \ldots 0,6 \mathrm{~m}^{3} /\right.$ хвил.) кут розкриття ГРП сягає $2 \ldots 5$ град. При $l_{\mathrm{C}} / d_{0}=2$ збільшення витрати нейтрального газу призводить до підвищення кута розкриття до 15 град, що у промислових умовах буде мати негативний вплив на результати вуглецевого розкислення.

Результати наступного етапу досліджень [4] з визначенням характеру та ступеня впливу кута розкриття газометалевого потоку на створення захисної газової оболонки навколо останнього, були використані для отримання математичної залежності вмісту кисню при зміні витрат нейтрального газу з урахуванням довжини реакційної зони. (У технічно чистому аргоні, який використовували для вдування у робочий простір сталевипускного каналу, вміст кисню складав $0,9-1,1 \%)[4]$. 


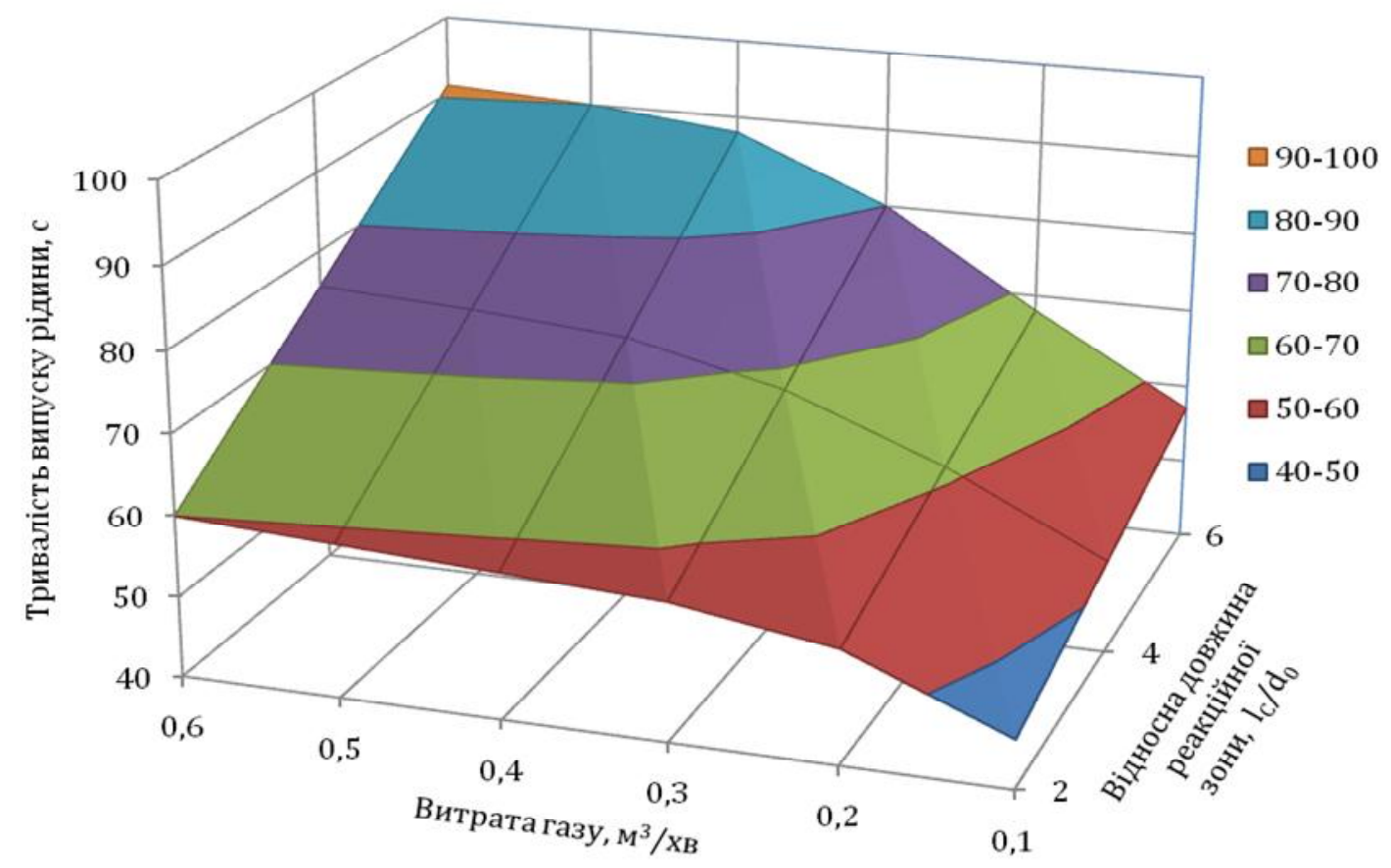

Puc. 2. Вплив витрати нейтрального газу та довжини реакційної зони на тривалість випуску газорідинного потоку для двокамерного сталевипускного каналу

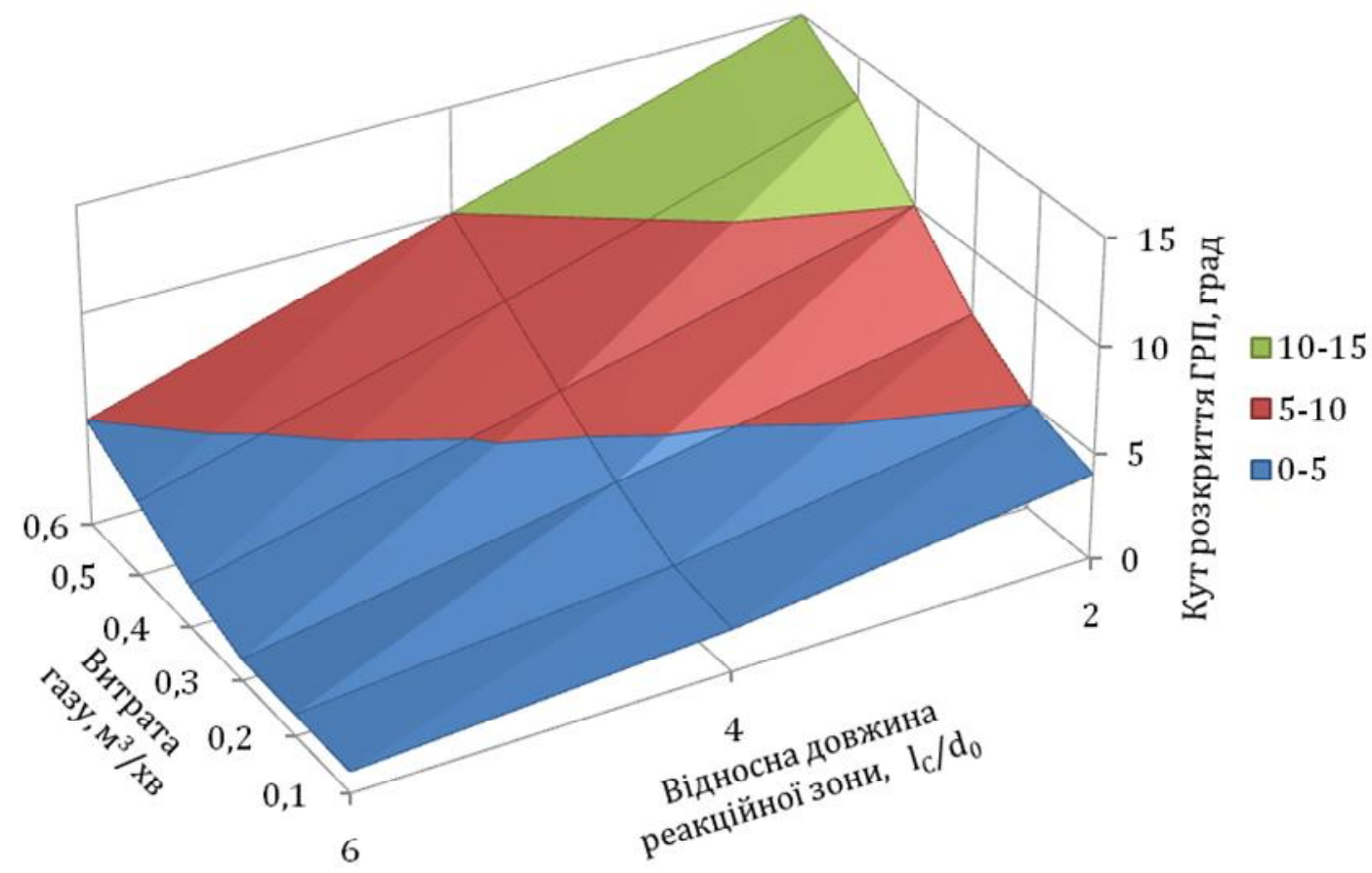

Рuc. 3. Вплив витрати газу та довжини реакційної зони на кут розкриття газорідинного потоку 
Отримана за результатами фізичного моделювання [4] математична модель залежності вмісту кисню у газовій складовій газорідинного потоку (ступеня розкисленості потоку) має вигляд

$$
\begin{gathered}
Z(x, y)=0.14 x+21.4 y+1.74 x y^{2}+1.79 y^{2}-4.23 x y+0.48 \\
\text { при } 2 \leq x \leq 6,0.1 \leq y \leq 0.6 .
\end{gathered}
$$

Результати чисельного експерименту з використанням виразу (5) представлені на рис. 4.

Виявлений у ході як фізичного [4], так і чисельного експерименту (рис. 4) захисний ефект нейтральної газової оболонки проявляється вже при мінімальній (у дослідженому діапазоні) витраті нейтрального газу $\left(0,1 \mathrm{~m}^{3} /\right.$ хвил.). В той же час, при зменшенні відносної довжини реакційної зони вміст кисню у потоці підвищується та сягає 10\%, що однозначно пов’язане зі зміною ступеню організації потоку.

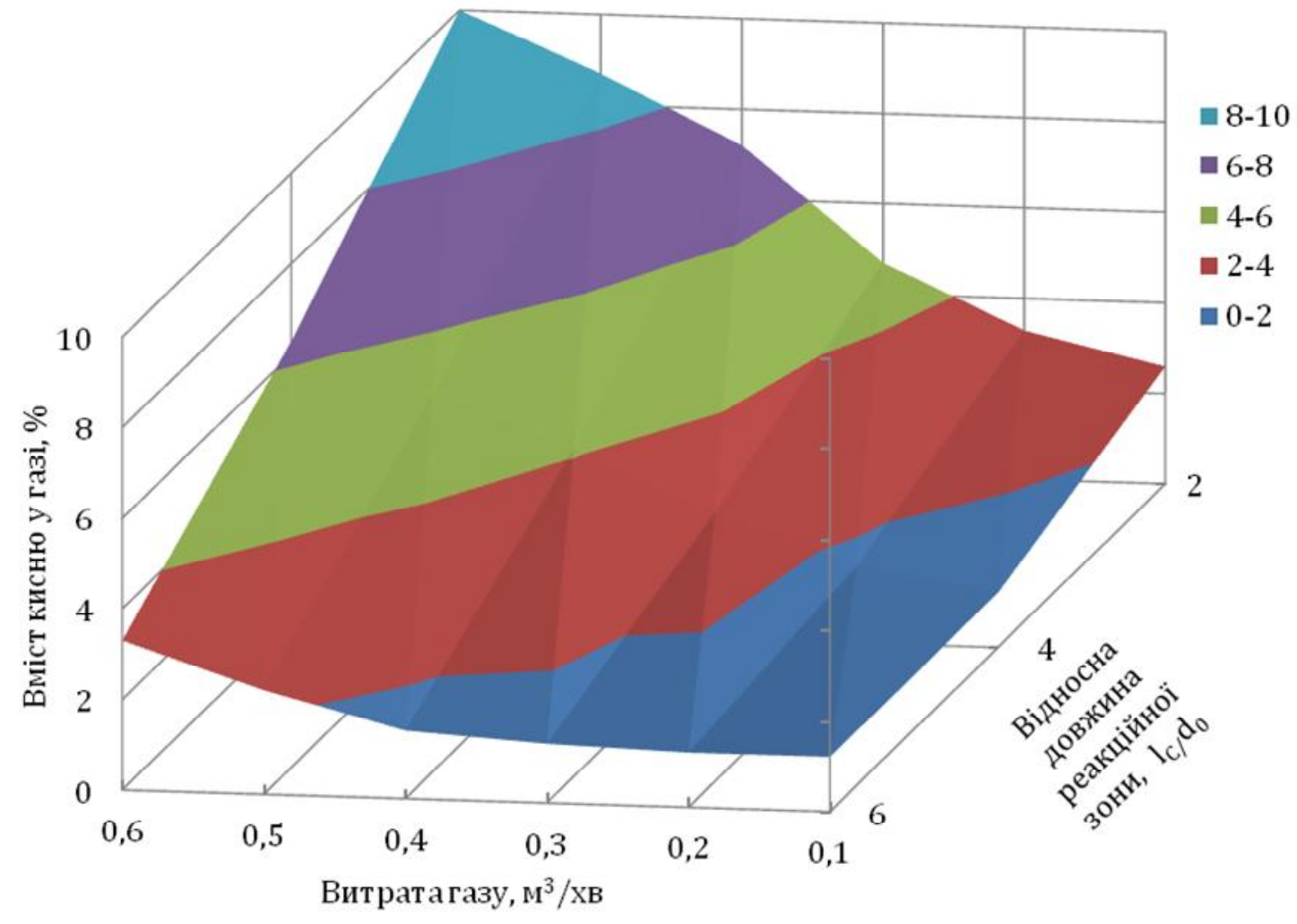

Pис. 4. Вплив витрати газу та довжини реакційної зони на залишковий вміст кисню у газометалевому потоці на виході з каналу

Для узагальнення даних, отриманих за результатами чисельного моделювання, побудований графік впливу ступеня організації потоку на залишковий вміст кисню в газах, що відходять на випуску металевого розплаву з конвертера у сталерозливний ківш (рис. 5).

Таким чином, підтверджено (рис. 5), що між кутом розкриття газометалевого потоку та вмістом кисню у газах, що відходять, існує безпосередній зв'язок. Встановлено, що для підвищення захисного ефекту нейтрального газу необхідно підвищувати ступінь організації (зменшенням кута розкриття) газометалевого потоку, що може бути забезпечено шляхом удосконалення сталевипускного каналу з переходом до двокамерної конструкції [5] останнього. 


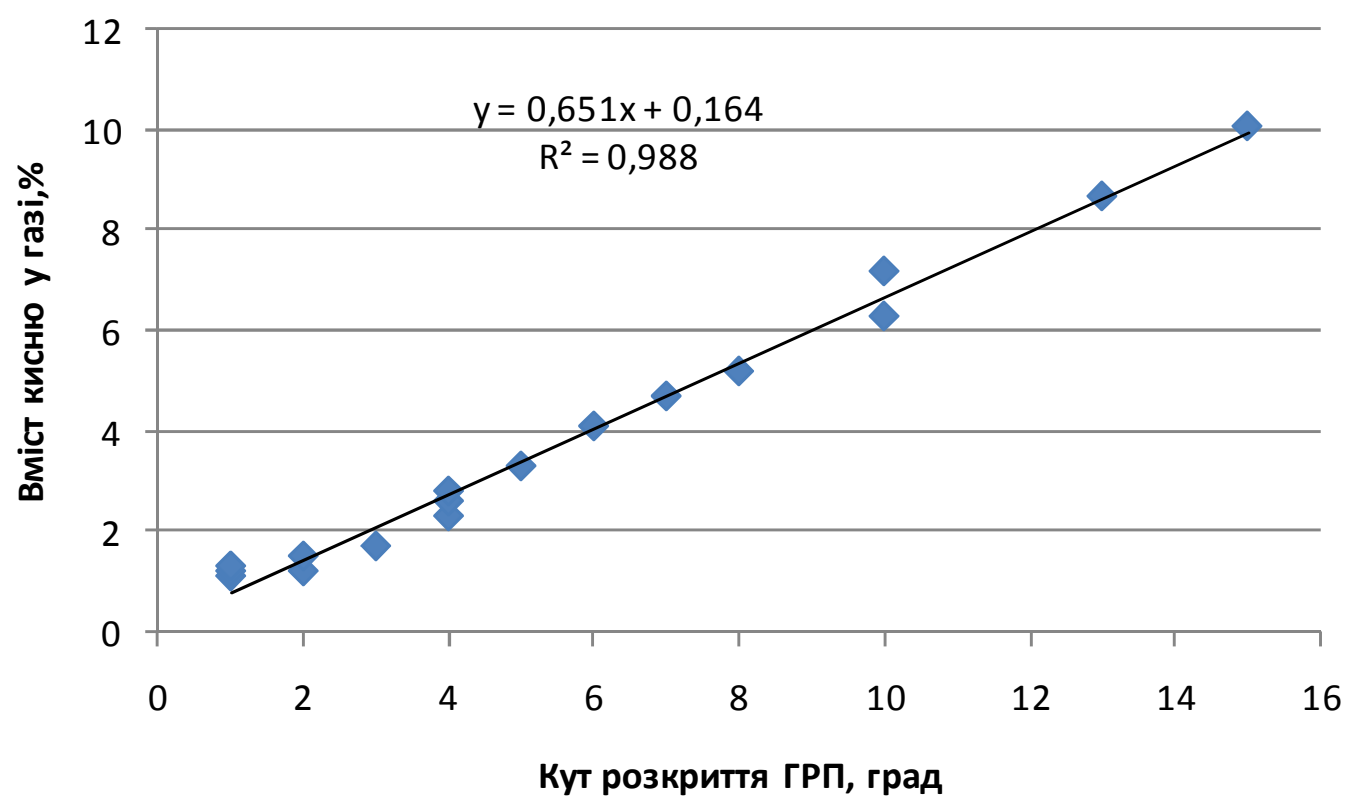
відходять

Рuc. 5. Вплив ступеня організації газометалевого потоку на вміст кисню у газах, що

\section{Висновки}

Представлені математичні моделі для дослідження впливу конструктивних та технологічних характеристик організації вуглецевого розкислення металевого розплаву на випуску у сталерозливний ківш за рахунок вдування нейтрального газу у робочий простір сталевипускного каналу кисневого конвертера. За результатами чисельного моделювання доведено, що застосування іноваційної двокамерної конструкції сталевипускного каналу кисневого конвертера, здатне забезпечити підвищення ступеня організації газометалевого потоку та його захист від атмосферного впливу.

\section{Список використаної літератури}

1. Моделирование выпуска расплава из конвертера с применением метода диаграмм связей / А.А. Похвалитый, Е.Н. Сигарев, А.Д. Кулик, В.П. Полетаев // Математическое моделирование. -2016 . - № 2(35). - С. 93-96.

2. Совершенствование выпуска стали из конвертера. Двухкамерная летка / А.А. Похвалитый, А.П. Огурцов, А.Д. Кулик, М.А. Кащеев // Черная металлургия: бюллетень науч.-техн. и экон. информ. - 2015. - № 6. - С. 16-19.

3. Повышение эффективности технологии выпуска металла из конвертера. Модель взаимодействия струи с газом в полости летки (сообщение 1) / А.П. Огурцов, А.Д. Кулик, М.А. Кащеев [и др.] // Сборник научных трудов Днепродзержинского государственного технического университета (технические науки) - 2013. - № 3(23). - С. 21-26.

4. Высокотемпературное моделирование выпуска плавки из конвертера с подачей аргона в полость летки / А.А. Похвалитый, А.Д. Кулик, Е.Н. Сигарев [и др.] // Металлургическая и горнорудная промышленность. - 2016. - № 2. - С. 52-57.

5. Декл. пат. на кор. мод. України 93239 / Спосіб позапічної обробки металу; С21С 7/072, С21C 5/46, С21C 5/42 // А.П. Огурцов, А.Д. Кулик, М.А. Кащеєв, А.А. Похвалітий, В.О. Дерипаско. - № u201403532; Заявл. 07.04.2014; Опубл. 25.09.2014, бюл. № 18. 